\title{
Risk taking and sharing when risk exposure is interdependent
}

\section{Abigail Barr ${ }^{1}$, Trudy Owens ${ }^{2}$ and Ashira Perera ${ }^{3}$}

\section{March 2020}

Abstract: Using a specially designed experiment, we investigate whether and how interdependence in risk exposure i.e., risk taking by some members of a potential risk sharing group affecting not only their own but also their co-members risk exposure, affects both risk taking and ex post sharing. The experimental subjects were Sri Lankan small-holders who face interdependent risk and share when neighbors fall on hard times in everyday life. We find that the Sri Lankan farmers reward socially responsible risk taking and, under some circumstances, punish socially irresponsible risk taking. Their behavior is consistent with socially responsible risk taking being cost-dependent, although, here, the statistical evidence is inconclusive. Finally, social responsibility in risk taking and ex post sharing do not appear to be substitutes, rather, they appear to be co-determined.

Keywords: behavioural experiment; risk-sharing; solidarity.

JEL Classifications: C93, D81, O12.

Acknowledgements: This work was supported by the British Academy/Leverhulme Small Research Grants Programme [grant number SG130600]. We are grateful to Arthacharya Foundation/Arthavida Intermediary for their advice and assistance during the fieldwork, to our dedicated team of field research assistants, and to all of our experimental participants. This paper does not reflect the views of Oxford Policy Management.

${ }^{1}$ Abigail Barr: Affiliation - University of Nottingham; Address - School of Economics, University of Nottingham, University Park, Nottingham, NG7 2RD, UNITED KINGDOM. ORCID: 0000-0002$1241-9162$

${ }^{2}$ Trudy Owens: Affiliation - University of Nottingham; Address - School of Economics, University of Nottingham, University Park, Nottingham, NG7 2RD, UNITED KINGDOM. ORCID: 0000-00018676-2919

${ }^{3}$ Ashira Perera: Affiliation - Oxford Policy Management; Address - Oxford Policy Management, The Clarendon Centre, 52 Cornmarket St, Oxford, OX1 3HJ

Corresponding author: Abigail Barr; abigail.barr@ nottingham.co.uk 


\section{Risk taking and sharing when risk exposure is interdependent}

\section{Introduction}

Levels of environmental risk are increasing across many locations worldwide (IPCC, 2014). Poor farmers in developing countries are particularly vulnerable to these increases (Baettig et al., 2007; Füssel, 2010; World Bank, 2010; Sherbinin, 2014; Rosenzweig et al., 2014). While efforts are being made to make micro insurance available to these farmers, it will take time to bring access to such products to scale and, in trials, take-up has been very low (Cole et al., 2012; Greatrex et al., 2015; Platteau et al., 2017). The traditional form of risk pooling, involving ex post transfers from "lucky" to "unlucky" people within small communities and kinship networks, is still heavily relied upon as a coping mechanism and is likely to remain so for the foreseeable future (Udry, 1994; Fafchamps and Lund, 2003; Takasaki et al., 2004; Rondeau and Bulte, 2007; Bramoullé and Kranton, 2007; Porter, 2012; Platteau et al., 2017). We know that this traditional form of risk pooling is an effective mechanism for smoothing consumption when risk is idiosyncratic, but fails when risk is co-variate within the risk pooling group (Townsend, 1994; Dercon, 2002; Fafchamps, 2011; Barrett et al., 2011; de Janvry et al., 2014; Sawada et al., 2017). However, little is known about how risk taking by pooling group members impacts on ex post transfers. And even less is known about how interdependence in risk exposure, i.e., risk taking by some members affecting not only their own but also their comembers' risk exposure, impacts on ex post transfers. In this paper, we take a first step towards filling this gap in our knowledge by engaging Sri Lankan small-scale farmers in a novel labtype behavioural experiment.

In behavioural experiments involving students, risk taking by or for groups compared to by individuals for only themselves, tends to be more conservative, i.e., consistent with higher 
levels of risk aversion, especially in high risk situations (Baker et al., 2008; Shupp and Williams, 2008; Reynolds et al., 2009; Masclet et al., 2009, Bolton et al., 2015). Bolton et al. (2015) found that this was owing to risk takers assuming a degree of "social responsibility" rather than because they were endeavouring to take the preferences of other group members into account. Using a structural modelling approach, Vieider et al. (2016) find that probability weighting for gains and losses becomes more extreme when players are responsible for not only their own but also others' payoffs. However, in Vieider et al. (2016) and in the experiments just described the possibility of ex post redistribution was excluded by design.

The literature on experiments involving opportunities for ex post redistribution of gamble outcomes started with Selten and Ockenfels (1998). In their solidarity game each of three players faced a $2 / 3$ probability of receiving a positive sum of money and had to decide, prior to outcomes being realised, how much they would give to one or each of two losers in the event they (the decision-maker) wins. The majority of their student subjects were willing to give substantial amounts. More recently, Cappelen et al. (2013) conducted an experiment to investigate whether subjects' (again students) redistributive decisions depend on whether inequality emerges as a consequence of choice or luck. Their student subjects redistributed more in the direction of equality when subjects made the same risk taking choice, i.e., when inequalities were owing to luck alone. This finding is directly relevant to the issue of how risk taking by pooling group members impacts on ex post transfers.

In a related line of research, Zizzo and Oswald (2001) and Kebede and Zizzo (2011) allowed subjects to choose how much to invest in a high return but risky prospect and, following the realisation of investment outcomes, at a cost to themselves, burn other subjects' money. The study by Kebede and Zizzo (2011) is particularly relevant because their subjects were small- 
scale farmers in Ethiopia. The farmers burned a lot of money and their burning decisions were consistent with inequality aversion in the form of envy. Further, in villages where there was more money burning there was less agricultural innovation in every-day life. These experiments relate, albeit indirectly, to the issue of how risk taking by pooling group members impacts on ex post transfers. However, by design, they exclude both helping via positive transfers and the possibility of interdependence in risk exposure.

To our knowledge, only one experiment has been conducted with the stated objective of investigating how individual risk taking impacts on risk pooling. Cettolin and Tausch's (2015) experiment involved a game in which two players either chose or were assigned gambles and then one, having been informed of their co-player's gamble choice but prior to the realisation of the gamble outcomes, had to decide what proportion of their earnings should be pooled and shared equally. They found that risk averse subjects prefer not to ex ante pool with high risk takers. However, the focus of this experiment was on ex ante rather than ex post risk pooling.

Our experimental design is most closely related to those of Cappelen et al. (2013) and Bolton et al. (2015). The principal distinguishing feature of our experiment compared to Cappelen $e t$ al.'s (2013) is that, in common with Bolton et al. (2015), we include treatments in which some players' levels of risk exposure are owing to the risk taking choices made by other players, i.e., risk exposure is interdependent. And in our analysis we focus on whether and how this interdependence affects both risk taking and ex post redistribution, i.e., sharing. To formulate predictions regarding these behaviours, we combine Bolton et al.'s (2015) notion of socially responsible risk taking with elements of Cox et al.'s (2007) model of reciprocity and fairness.

Especially when thinking about efforts by small-scale farmers to mitigate environmental risks and interventions by development agencies to support those efforts, interdependence in risk 
exposure looms large. Consider, for example, one farmer improving his flood defences and, thereby, increasing the flood risk to another farmer nearby. Or one farmer strengthening his defences against landslips and, thereby, reducing the risk to his neighbour just down the hill. We need to know how such interdependencies impact on both risk taking and ex post sharing behaviour so that we can ensure that the support offered to farmers is optimally designed.

Initially, with this in mind, we considered designing a highly contextualised experiment, i.e., one in which the tasks were framed in such a way that they evoked local, every day decisionmaking conditions. However, informal risk pooling is an on-going process, involving a potentially infinite series of transfers between a potentially very large number of risk-pool members, and risk taking or mitigating decisions take many, diverse forms, so, some level of abstraction was inevitable. Further, had we felt able to tailor our experiment to our subjects and their circumstances (described in Section 2.3), and done precisely that, our findings would have been of little relevance to anyone other than our subjects and others facing the same circumstances. Here, the prescription of Friedman and Sunder (1994), that one's "goal should be to find a design that offers the best opportunity to learn something useful and answer the questions that motivate [ones] research" (p.11), loomed large. So, we chose a path that started with a very clearly defined set of research questions and then drew on the existing, relevant experimental literature (summarised above) to develop an experimental design that would maximised our chances of generating useful insights.

Our four research questions are as follows: Is socially responsible risk taking rewarded? Is socially irresponsible risk taking punished? Is social responsibility in risk taking costdependent? And, Are social responsibility in risk taking and ex post sharing substitutes? It is reasonable to expect that socially responsible behaviour will be rewarded or, at least, not 
punished. Within the context we are interested in, this would translate into a farmer who is exposed to less (more) risk, owing to the risk taking decisions of another farmer, being more (less) inclined to help that other farmer in the event that he (the other farmer) is unlucky. If this is what we observe, there is a case for promoting socially responsible risk taking. Our interdependent risk exposure treatments combined with a treatment in which risk exposure is randomly allocated allow us to investigate this. In the presence of interdependence in risk exposure, socially responsible risk takers might have to choose levels of risk exposure for themselves that are not directly consistent with their own risk preferences. Thus, socially responsible risk taking is costly and that cost will depend on the nature of the interdependence and decision makers' level of risk aversion. Gaining an understanding of whether and how such costs impact on decision-making will inform the design of interventions aimed at promoting socially responsible risk taking. Our interdependent risk exposure treatments, combined with a treatment in which subjects choose their own risk exposure but there is no interdependence, allow us to investigate this. Finally, socially responsible risk taking and sharing are both positively other-regarding behaviours and, this being the case, they may be substitutes. Alternatively, but for the same reasons, they may be co-determined. Which of these is the case has important implications for the possible effects of interventions aimed at promoting socially responsible risk taking on the efficacy of traditional risk pooling as a mechanism for coping with environmental risk.

We find that the Sri Lankan farmers in our sample reward socially responsible risk taking and, under some circumstances, punish socially irresponsible risk taking. Their behaviour in the experiment is consistent with socially responsible risk taking being cost-dependent. However, here, the statistical evidence is inconclusive. Finally, social responsibility in risk taking and $e x$ post sharing do not appear to be substitutes, rather, they appear to be co-determined. 
The remainder of the paper is organised as follows: Section 2 presents our experimental design; Section 3 describes our conceptual framework and sets out predictions relating to each of our research questions; Section 4 presents our results; and, finally, Section 5 concludes.

\section{Experimental design}

\subsection{The Risk-and-sharing game}

The RSG is played in pairs. At the start of the game each player chooses or is assigned either the safer or the riskier of two gambles. Each gamble yields a high payoff with probability 0.5 and a low payoff with probability 0.5 . The payoff from the gamble assigned to or chosen by a subject is determined by playing a which-hand-is-it-in game that involves the subject guessing which of the researcher's hands contains a blue rather than a yellow counter. If the player finds the blue counter, she receives the high payoff. If she finds the yellow counter, she receives the low payoff. Table 1 presents the two gambles, their expected values, and standard deviations. ${ }^{1}$

Table 1: Risk and sharing game gambles

\begin{tabular}{ccccc}
\hline Gamble & Low $\begin{array}{c}\text { payoff } \\
\text { (Rs.) }\end{array}$ & $\begin{array}{c}\text { High payoff } \\
\text { (Rs.) }\end{array}$ & $\begin{array}{c}\text { Expected value } \\
\text { (Rs.) }\end{array}$ & $\begin{array}{c}\text { Standard } \\
\text { deviation (Rs.) }\end{array}$ \\
\hline Safer & 360 & 760 & 560 & 200 \\
Riskier & 80 & 1520 & 800 & 720 \\
\hline
\end{tabular}

Under the baseline treatment half of the players are randomly assigned the safer gamble and half the riskier gamble. Below, this treatment is referred to as $R A N D$. Prior to realising the outcomes of their gambles, each player is presented with the set of scenarios within which she

1 The visual aid used to explain the gambles to the participants is presented in Figure A4 in the Online Supplementary Materials. 
is richer than her co-player once both of their gamble outcomes have been realised. For each scenario, each player must decide whether to "share", i.e., redistribute so as to equalise earnings from the game, or "leave" the payoffs as they are. All the possible scenarios that players may face are set out in Table 2. If a player is assigned the safer gamble, she must decide whether to share or leave in Scenarios 1, 2, and 3. If a player is assigned the riskier gamble, she must decide whether to share or leave in Scenarios 4, 5 and 6.

Table 2: RSG sharing scenarios

\begin{tabular}{cll}
\hline Scenario & Own gamble payoff from gamble & Co-player's gamble payoff \\
\hline 1 & High from safer gamble (Rs.760) & Low from safer gamble (Rs.360) \\
2 & High from safer gamble (Rs.760) & Low from riskier gamble (Rs.80) \\
3 & Low from safer gamble (Rs.360) & Low from riskier gamble (Rs.80) \\
4 & High from riskier gamble (Rs.1520) & High from safer gamble (Rs.760) \\
5 & High from riskier gamble (Rs.1520) & Low from safer gamble (Rs.360) \\
6 & High from riskier gamble (Rs.1520) & Low from riskier gamble (Rs.80) \\
\hline
\end{tabular}

Once all decisions have been made, the gambles are played out. Then, if the players' gamble payoffs are unequal, the prior share-or-leave decision of the player with the higher payoff in the relevant scenario is used to determine both players' final earnings from the game. If the players' gamble payoffs are the same, their final earnings from the game equal those gamble payoffs. Subjects are talked through the entire game before making any decisions.

Under the CHOS treatment (also used as a baseline in some analyses) the game is the same except that each player chooses either the safer or the riskier gamble. If a player chooses the safer gamble, she must decide whether to share or leave in Scenarios 1,2, and 3. If a player chooses the riskier gamble, she must decide whether to share or leave in Scenarios 4, 5 and 6.

Interdependence in risk exposure is introduced in two further treatments, the IDSG and IDDG treatments. The IDSG treatment consists of two sub-treatments: IDSG chooser and IDSG 
chosen-for. In IDSG sessions, players are randomly assigned to either the IDSG chooser or the IDSG chosen-for sub-treatment and each playing pair is made up of one chooser and one chosen-for player. An IDSG chooser must choose either the safer or the riskier gamble for herself and her co-player. If an IDSG chooser chooses the safer gamble for both players, she must also decide whether to share or leave in the event that Scenario 1, where her gamble payoff is greater than her co-player's, arises. If an IDSG chooser chooses the riskier gamble for both players, she must also decide whether to share or leave in the event that Scenario 6 arises. An IDSG chosen-for player must decide whether to share or leave under Scenario 1, in which she ends up the richer after her co-player chooses the safer gamble for both, and Scenario 6, in which she ends up the richer after her co-player chooses the riskier gamble for both.

The IDDG treatment also consists of two sub-treatments: IDDG chooser and IDDG chosenfor. In $I D D G$ sessions, players are randomly assigned to either the IDDG chooser or the IDDG chosen-for sub-treatment and each playing pair is made up of one chooser and one chosen-for player. An IDDG chooser must choose either the safer or the riskier gamble for herself in the knowledge that her co-player will face the residual gamble, i.e., if an IDDG chooser chooses the safer (riskier) gamble for herself, her co-player will face the riskier (safer) gamble. If an $I D D G$ chooser chooses the safer gamble for herself, she must decide whether to share or leave in Scenarios 2 and 3. If an IDDG chooser chooses the riskier gamble for herself, she must decide whether to share or leave in Scenarios 4 and 5. An IDDG chosen-for player must decide whether to share or leave under Scenarios 2 and 3, in which she ends up the richer after her coplayer chooses the riskier gamble for herself and thereby the safer gamble for the chosen-for player, and Scenarios 4 and 5, in which she ends up the richer after her co-player chooses the safer gamble for herself and thereby the riskier gamble for the chosen-for player. 
Our use of the strategy method to elicit the subjects' share-or-leave decisions in the RSG is worthy of note. First, it is non-standard in the sense that the strategy-space varied from subject to subject depending on the treatment to which they were assigned and the gamble that they chose or that was chosen or randomly selected for them. This is unavoidable, but needs to be born in mind. Second, as always, one needs to consider the possible implications of strategy method use for one's findings. Of potential concern, here, is the evidence presented by Brandts and Charness (2011) that the method reduces subjects' willingness to punish. However, punishment within the RSG involves refraining from sharing and is identified through crosstreatment comparisons and Brandts and Charness (2011) found no evidence of the method changing the size or significance of treatment effects. Further, the use of the strategy method in the RSG yields a significant advantage because, in accordance with risk pooling in everyday life, it allows us to invite the subjects to make ex post sharing decisions, i.e., decision based on known risk outcomes for both self and playing partner. Had we not used the strategy method, to render it possible for subjects to make such ex post sharing decisions, we would have had to engage each subject in two one-on-one interviews within the RSG. ${ }^{2}$ This would have made the experimental sessions procedurally very difficult, if not impossible, to run and control. In addition, use of the method increases the number of observations one can generate from a given subject sample, reduces the cost per observation and, thus, increases statistical power.

Each participant played the RSG once under one of the treatments. Treatments were assigned at the session level (more on this below). Participants were randomly paired within sessions. Each knew that they were paired with a fellow villager attending the same session, but would never know the identity of their co-player.

\footnotetext{
${ }^{2}$ In the first they would have chosen and/or played out their risk and, in the second, they would have learnt the own and their partner's risk outcomes and made their sharing decisions.
} 


\subsection{The Gamble Choice Task}

To generate a measure of each subject's level of risk aversion, immediately prior to the RSG, the subjects undertook a Binswanger-type (1980) gamble choice (GC) task. Each had to choose one out of six gambles. The gamble choice set was identical to the one used by Barr and Genicot (2008) in the first lab-in-the-field risk-sharing experiment and to Binswanger's (1980) original gamble choice set with the dominated choices removed. Every gamble yielded either a high or low payoff, each with probability 0.5 . The payoff from the chosen gamble was determined by playing the which-hand-is-it-in game described above. Table 3 presents the six gambles, their expected values, standard deviations and the Cole et al. (2013) measure of risk aversion associated with each choice. ${ }^{3}$ The task was designed specifically to measure risk aversion and, hence, the expected values and standard deviations are positively correlated and a risk seeker is bound to choose F. The Cole et al. (2013) measure of risk aversion captures the maximum rate at which the gamble chooser is willing to accept additional risk (standard deviation) in return for a higher expected value. It is constructed as follows. The measure is set equal to one if the least risky option (Gamble A) is chosen. Then, for each of the other gamble choices it equals the expected value of that gamble minus the expected value of the consecutive and safer gamble in the series divided by the difference in standard deviation between the same two gambles.

\footnotetext{
3 The visual aid used to explain the gambles to the participants is presented in Figure A.5.3 in the Online Supplementary Materials.
} 
Table 3: Gamble Choice Task Choices

\begin{tabular}{cccccc}
\hline Gamble & $\begin{array}{c}\text { Low } \\
\text { payoff } \\
(\text { Rs. })\end{array}$ & $\begin{array}{c}\text { High } \\
\text { payoff } \\
(\text { Rs. })\end{array}$ & $\begin{array}{c}\text { Expected } \\
\text { value } \\
(\text { Rs. })\end{array}$ & $\begin{array}{c}\text { Standard } \\
\text { deviation } \\
(\text { Rs. })\end{array}$ & $\begin{array}{c}\text { Cole } \text { et al. (2013) } \\
\text { measure of risk } \\
\text { aversion }\end{array}$ \\
\hline A & 200 & 200 & 200 & 0 & 1.00 \\
B & 180 & 380 & 280 & 100 & 0.80 \\
C & 160 & 480 & 320 & 160 & 0.67 \\
D & 120 & 600 & 360 & 240 & 0.50 \\
E & 40 & 760 & 400 & 360 & 0.33 \\
F & 0 & 800 & 400 & 400 & 0.00 \\
\hline
\end{tabular}

\subsection{Participants and treatment assignments}

The experiment was conducted in 16 villages in Wellawaya district, Sri Lanka. ${ }^{4}$ The smallholder farmers rely heavily on the traditional form of risk pooling described above and, to varying degrees, they are exposed to the Human-Elephant Conflict, an environmental risk which is interdependent in nature. The decisions of one farmer to mitigate against elephantrelated crop damage, e.g. by keeping watch, sounding horns and igniting firecrackers and/or by installing an electric fence, have direct consequences on the risk exposure of and outcomes for neighbouring farmers.

In each village, 32 household heads were randomly sampled from the 2012/13 Electoral Register. Each of these household heads was invited to participate in a one-day workshop to be conducted in their village. Where the household head was unable to attend, the next most important decision-maker in the family was invited to participate.

\footnotetext{
${ }^{4}$ Falk et al. (2015) found that, in general, Sri Lankans exhibit high levels of positive reciprocity and altruism, but fairly low levels of negative reciprocity, compared to the global average.
} 
Each village workshop was made up of two experimental sessions and two survey-completing sessions. Each invited subject participated in one experimental session and one surveycompleting session. We conducted 6 sessions under RAND, 6 sessions under $C H O S, 10$ under $I D S G$ and 10 under IDDG. RSG treatments were assigned at the session level with different treatments assigned to the two sessions in any one village with the aim of ensuring balance across treatments with regard to village characteristics and time of day.

Table 4: Subject characteristics, including risk aversions, by RSG Treatments and SubTreatments

\begin{tabular}{|c|c|c|c|c|c|c|c|}
\hline Treatment & $A L L$ & $R A N D$ & CHOS & $\begin{array}{r}\boldsymbol{I L} \\
\text { chooser }\end{array}$ & $\begin{array}{l}\boldsymbol{S G} \\
\text { chosen-for }\end{array}$ & $\begin{array}{r}\text { II } \\
\text { chooser }\end{array}$ & $\begin{array}{l}D G \\
\text { chosen-for }\end{array}$ \\
\hline $\begin{array}{l}\text { Household } \\
\text { head }\end{array}$ & $\begin{array}{c}0.41 \\
(0.49)\end{array}$ & $\begin{array}{c}0.35 \\
(0.48)\end{array}$ & $\begin{array}{c}0.43 \\
(0.50)\end{array}$ & $\begin{array}{c}0.45 \\
(0.50)\end{array}$ & $\begin{array}{c}0.42 \\
(0.50)\end{array}$ & $\begin{array}{c}0.38 \\
(0.49)\end{array}$ & $\begin{array}{c}0.41 \\
(0.50)\end{array}$ \\
\hline Female & $\begin{array}{c}0.67 \\
(0.47)\end{array}$ & $\begin{array}{c}0.71 \\
(0.45)\end{array}$ & $\begin{array}{c}0.62 \\
(0.49)\end{array}$ & $\begin{array}{c}0.59 \\
(0.50)\end{array}$ & $\begin{array}{c}0.71 \\
(0.46)\end{array}$ & $\begin{array}{c}0.74 \\
(0.44)\end{array}$ & $\begin{array}{c}0.64 \\
(0.48)\end{array}$ \\
\hline Age & $\begin{array}{l}44.31^{\mathrm{a}} \\
(13.74)\end{array}$ & $\begin{array}{l}40.48^{b} \\
(12.67)\end{array}$ & $\begin{array}{c}46.10 \\
(13.42)\end{array}$ & $\begin{array}{c}45.24 \\
(14.55)\end{array}$ & $\begin{array}{c}43.34 \\
(14.50)\end{array}$ & $\begin{array}{c}45.51 \\
(13.31)\end{array}$ & $\begin{array}{l}45.38^{c} \\
(13.62)\end{array}$ \\
\hline $\begin{array}{l}\text { Education } \\
\text { (years) }\end{array}$ & $\begin{array}{l}8.83^{\mathrm{c}} \\
(3.70)\end{array}$ & $\begin{array}{l}8.45 \\
(3.85)\end{array}$ & $\begin{array}{l}8.85 \\
(3.58)\end{array}$ & $\begin{array}{l}8.43^{\mathrm{c}} \\
(3.98)\end{array}$ & $\begin{array}{l}9.25 \\
(3.81)\end{array}$ & $\begin{array}{c}8.84 \\
(3.60)\end{array}$ & $\begin{array}{c}9.22 \\
(3.83)\end{array}$ \\
\hline $\begin{array}{l}\text { H'hold income } \\
\text { (p.a. Rs.'000s) }\end{array}$ & $\begin{array}{l}209 \\
(261)\end{array}$ & $\begin{array}{c}204 \\
(303)\end{array}$ & $\begin{array}{c}220 \\
(239)\end{array}$ & $\begin{array}{l}196 \\
(236)\end{array}$ & $\begin{array}{c}194 \\
(272)\end{array}$ & $\begin{array}{c}233 \\
(275)\end{array}$ & $\begin{array}{c}209 \\
(236)\end{array}$ \\
\hline $\begin{array}{l}\text { Risk aversion } \\
\text { (Cole } \text { et al, })\end{array}$ & $\begin{array}{c}0.53 \\
(0.25)\end{array}$ & $\begin{array}{c}0.56 \\
(0.27)\end{array}$ & $\begin{array}{c}0.55 \\
(0.23)\end{array}$ & $\begin{array}{c}0.50 \\
(0.24)\end{array}$ & $\begin{array}{c}0.51 \\
(0.26)\end{array}$ & $\begin{array}{c}0.51 \\
(0.27)\end{array}$ & $\begin{array}{c}0.55 \\
(0.23)\end{array}$ \\
\hline \multicolumn{8}{|c|}{ Gamble Choice distributions: } \\
\hline Gamble A & 0.08 & 0.11 & 0.05 & 0.07 & 0.11 & 0.07 & 0.08 \\
\hline Gamble B & 0.10 & 0.15 & 0.11 & 0.07 & 0.05 & 0.11 & 0.13 \\
\hline Gamble C & 0.17 & 0.15 & 0.25 & 0.17 & 0.10 & 0.18 & 0.15 \\
\hline Gamble D & 0.46 & 0.39 & 0.45 & 0.44 & 0.52 & 0.45 & 0.50 \\
\hline Gamble E & 0.08 & 0.08 & 0.04 & 0.15 & 0.10 & 0.05 & 0.08 \\
\hline Gamble F & 0.11 & 0.11 & 0.10 & 0.11 & 0.12 & 0.15 & 0.08 \\
\hline Subjects & 466 & 84 & 79 & 76 & 73 & 74 & 80 \\
\hline
\end{tabular}

Notes: Means and standard deviations (in parentheses) presented; ${ }^{a}$ three missing values; ${ }^{\mathrm{b}}$ two missing values; ${ }^{c}$ one missing value; differences between the numbers of choosers and the numbers of chosenfors in the IDSG and IDDG treatments are owing to the sub-treatment assignment by badge picking combined with no-shows. 
Of the 512 households that received an invitation, 467 sent a representative who participated in a workshop. Of these, 41 percent were household heads (43 female, 145 male) and 54 percent were spouses of household heads and the next most important, if not equally important, decision-maker in the household. Most of the remaining 11 were parents of household heads.

On arrival at a workshop, each subject randomly picked a badge. Half of the badges were labelled "AM session" and, half "PM session", and each badge also bore an ID number. Prior to each session, ID numbers were randomly matched into RSG playing pairs and, in the IDSG and $I D D G$ treatments, randomly assigned to roles. Thus, the badge a subject picked determined his or her experimental session, and hence RSG treatment, playing pair in the RSG and, in the $I D S G$ and $I D D G$ treatments, RSG role.

Table 4 presents a summary of the subjects' characteristics, including their levels of risk aversion. Sixty-seven percent of the subjects were female and the average subject was just over 44 years in age and had just under 9 years of education and an annual household income of approximately 209 thousand Rupees. The average subject's level of risk aversion according to the Cole et al. (2013) measure derived from their GC gamble choices was 0.53 . The distribution of gamble choices has an unusually strong mode (46 percent) at Gamble D, which could be owing to the apparently large decline in the low payoff between Gambles D and E. ${ }^{56}$

According to linear regressions taking each of the variables household head, female, age, education, household income, and risk aversion as the dependent variable and treatment

\footnotetext{
${ }^{5}$ In Barr and Genicot (2008), the modal choice was also Gamble D, but its relative frequency was only 35 percent. ${ }^{6}$ To investigate whether this feature of the distribution of gamble choices affects the analyses below, we reestimate every model that contains the Cole et al. measure of risk aversion using a dummy variable $H R A$, which equals one if the subject chose gamble $\mathrm{A}, \mathrm{B}$ or $\mathrm{C}$, in its place and report the results in footnotes.
} 
assignment indicators as the explanatory variables, the treatment assignment was balanced. A chi-squared test indicates that gamble choices were also balanced across treatments.

\subsection{Implementation}

During each village workshop, "AM session" subjects participated in the experiment in the morning and the survey in the afternoon. The "PM session" subjects did the opposite. AM and PM subjects were not allowed to interact at any point during a workshop and no communication between subjects was allowed within each experimental session.

The experiments proceeded as follows. First, a research assistant described the GC task to all of the subjects in a session in Sinhala, the local language, following a pre-written script and using visual aids. ${ }^{7}$ Then, each player met with a research assistant in private and chose one of the six gambles. Once a player had made his or her gamble choice, he or she returned to the main seating area. Then, one of the research assistants described the RSG to all the participants in the session. Again, a pre-written script in Sinhala and a set of visual aids was used. ${ }^{8}$ Next, each player met with a research assistant in private. The research assistant described the RSG again and the subject made his or her RSG gamble choice and, if appropriate given their treatment assignment, their share-or-leave decisions in each of the relevant, given the treatment and his or her gamble choice, scenarios. The subject then returned to the main seating area.

Outcomes were realised at the end of the day upon completion of both experimental sessions in the village. ${ }^{9}$ Mean earnings from the GC and RSG were Rs. 341 and Rs. 675 respectively. ${ }^{10}$

\footnotetext{
${ }^{7}$ Scripts available from authors. See Table A2 for the visual aid.

${ }^{8}$ Scripts and visual aids available from authors.

${ }^{9}$ If a subject's assigned RSG co-player was a no-show, his or her payoff was calculated "as if" the co-player had made the modal choices given the treatment.

10 These amounts correspond to just under half a day's farm labour wage and just under a full day's farm labour wage for a male farm labourer, respectively.
} 
In addition to their earnings from the GC and RSG, subjects were paid their earnings from a public goods game and a show-up fee of Rs.250. They were also given lunch and refreshments.

\section{Conceptual framework and predictions}

In this section we draw on the behavioural and experimental literature to derive predictions relating to each of our four research questions: Is socially responsible risk taking rewarded? Is socially irresponsible risk taking punished? Is social responsibility in risk taking costdependent? And, Are social responsibility in risk taking and ex post sharing substitutes?

Before we can address these questions, we need to think about what socially responsible risk taking means within the context of the RSG. In Bolton et al. (2015), as in our IDSG treatment, the decision-maker chose a gamble either for herself or for both herself and a non-decisionmaking other and choosing a less risky gamble when also choosing for the non-decision-making other was described as socially responsible risk taking. However, note that choosing a less risky gamble when also choosing for the non-decision-making other both reduces the risk exposure of the non-decision-making other and of the pair as whole, and it is unclear whether both or just one of these is necessary for the action to be deemed socially responsible. If socially responsible risk taking equates to minimising the risk exposure of others, under $I D S G$, a socially responsible chooser will choose the safer gamble for both her chosen-for co-player and herself and, under $I D D G$, a socially responsible chooser will choose the safer gamble for her chosen-for co-player and, hence, the riskier gamble for herself. However, if socially responsible risk taking equates to minimising the risk exposure of the group, i.e., the pair within the RSG, while under IDSG, the socially responsible chooser will, once again, choose the safer gamble for both, under IDDG the socially responsible chooser will be indifferent between her two risk taking options. This is 
because the two options are equivalent in terms of risk exposure to the pair; they vary only with respect to the distribution of risk exposure between the chooser and chosen-for player.

Initially, we adopt minimising the risk exposure of others as our definition of socially responsible risk taking. However, at the end of this section, we revisit our predictions in the light of the other definition.

\subsection{Is socially responsible risk taking rewarded? Is socially irresponsible risk taking punished?}

"Socially responsible" implies kind and/or in accordance with a social norm or commonly held moral value. If, within the RSG, socially responsible risk taking is perceived in one of these ways by the chosen-for, we should expect the latter to positively reciprocate, reward, or at least not punish the chooser (Bolton and Ockenfels, 2000; Fehr et al. 2002; Cox, 2004, Dufwenberg and Kirchsteiger ,2004; Falk and Fischbacher, 2006; Bicchieri, 2006; Cox et al. 2007). Given our selected definition of socially responsible risk taking as minimising the risk exposure of others, it seems appropriate to think of it as an act that may be perceived as kind. Thus, we draw on Cox et al.'s (2007) model of reciprocity and fairness when developing our predictions. Under the IDSG and IDDG treatments in the RSG, positive reciprocation towards choosers can take only one form - a greater willingness on the part of the chosen-for to share in the event that they (the chosen-for) receive higher gamble payoffs than their chooser co-players. And punishment of socially irresponsible risk taking, also, can only take one form - a reduced willingness on the part of the chosen-for to share in the event that they (the chosen-for) receive higher gamble payoffs than their chooser co-players. To investigate whether socially responsible risk taking is rewarded and socially irresponsible risk taking punished we can compare chosen-fors' willingness to share in the IDSG and IDDG treatments, with willingness 
to share in the RAND treatment. Under the RAND treatment both players are chosen-for but not by their playing partner and, this being the case, they can infer nothing about the kindness or unkindness of their partner from the gamble they face and, so, have no motivation to reciprocate (Cox et al., 2007). All other things being equal, if socially responsible risk taking equates to minimising the risk exposure of others and is positively reciprocated, while socially irresponsible risk taking is punished:

- Prediction 1.1: a chosen-for subject under IDSG or IDDG who faces the safer gamble owing to the decision made by her chooser co-player will be more likely to share compared to a subject who is assigned the safer gamble under RAND.

- Prediction 1.2: a chosen-for subject under IDSG or IDDG who faces the riskier gamble owing to the decision made by her chooser co-player will be less likely to share compared to a subject who is assigned the riskier gamble under $R A N D$.

\subsection{Is social responsibility in risk taking cost-dependent?}

What socially responsible risk taking implies for the risk exposure of the chooser depends on her treatment assignment. In the IDSG treatment, a socially responsible chooser faces the safer gamble, while in the IDDG treatment, a socially responsible chooser faces the riskier gamble. Thus, the cost to a chooser of acting in a socially responsible way depends on her treatment assignment and her own level of risk aversion. Social responsibility is relatively low-cost (highcost) for risk averse choosers under IDSG (IDDG) and relatively low-cost (high-cost) for risk tolerant or neutral choosers under IDDG (IDSG). To find out whether social responsibility in risk taking is cost-dependent we can make use of our measure of risk aversion derived from the GC task in a comparison of risk taking under IDSG, IDDG and CHOS. 
All other things being equal, if acting in a socially responsible way is cost-dependent:

- Prediction 2.1: a chooser will be more likely to choose the safer gamble for herself under IDSG compared to a subject under $C H O S$;

- Prediction 2.2: the difference in the likelihood of a subject choosing the safer gamble for herself between IDSG and CHOS will be increasing in risk aversion;

- Prediction 2.3: a chooser will be less likely to choose the safer gamble for herself under $I D D G$ compared to a subject under CHOS; and

- Prediction 2.4: the difference in the likelihood of a subject choosing the safer gamble for herself between IDDG and CHOS will be decreasing in risk aversion.

\subsection{Are social responsibility in risk taking and sharing substitutes?}

Socially responsible risk taking and sharing are both positively other-regarding behaviours and, this being the case, may be substitutes. If they are substitutes, we should see a negative correlation between the two actions.

All other things being equal, if social responsibility in risk taking and sharing are substitutes:

- Prediction 3.1: under IDSG and IDDG, a chooser will be less likely to share if she chooses the safer gamble for her chosen-for co-player.

Of course, because socially responsible risk taking and sharing are both positively otherregarding behaviours, they may be co-determined, in which case we would expect them to be positively correlated. 


\subsection{What if socially responsible risk taking equates to minimising the risk exposure of the}

group?

If we adopt this alternative definition of socially responsible risk taking and assume that the only reason for chosen-for subjects' sharing behaviour to differ from that of subjects under $R A N D$ is because they wish to reward(punish) socially (ir)responsible risk takers, Predictions 1.1 and 1.2 will hold for the IDSG-RAND comparison but not for the IDDG-RAND comparison. Further, if we also assume that the only reason for choosers' behaviour to differ from that of subjects under $C H O S$ is because they wish to be socially responsible and, possibly, be rewarded and/or avoid punishment as a consequence, Predictions 2.1 to 2.4 will hold for the IDSG-CHOS comparison but not for the IDDG-CHOS comparison.

Under this definition, it seems inappropriate to think of socially responsible risk taking as an act of kindness directed towards a specific other and more appropriate to think of it as according with a social norm or commonly held moral value the upholding of which is rewardable and the violation of which is punishable (Bicchieri, 2006). Thus, our findings may generate some insights into what socially responsible risk taking means to Sri Lankan farmers.

\section{Results}

The upper panel of Table 5 presents the proportions of subjects exposed to the safer and riskier gambles under each of the RSG treatments. According to t-tests accounting for clustering at the session level, risk exposure varied markedly across treatments. Specifically, the proportion facing the safer gamble under $C H O S$, i.e., when they chose their exposure, was significantly higher than the proportion under $R A N D$, i.e., when risk exposure was randomly assigned $(p<0.01)$. The proportions facing the safer gamble under $I D S G$ was indistinguishable from both 
the proportion under $R A N D$ ( $p=0.26$ for choosers, $p=0.28$ for chosen-for) and the proportion under $\operatorname{CHOS}$ ( $p=0.32$ for choosers, $p=0.35$ for chosen-for). The proportion of IDDG choosers facing the safer gamble was significantly higher than the proportion under $\operatorname{RAND}(p<0.01)$, but statistically indistinguishable from the proportion under $\operatorname{CHOS}(p=0.31)$. And finally, the proportion of IDDG chosen-for players facing the riskier gamble was significantly higher than the proportions under RAND $(p<0.01)$ and $\operatorname{CHOS}(p<0.01)$.

Table 5: Risk exposure and sharing in the RSG

\begin{tabular}{lccccccc}
\hline Treatment & \multirow{2}{*}{ ALL } & RAND & CHOS & \multicolumn{2}{c}{ IDSG } & \multicolumn{2}{c}{ IDDG } \\
& & & & & & & \\
& & & & & & & \\
chooser & chosen-for & chooser & chosen-for \\
\hline Risk exposure: & & & & & & & \\
$\quad$ Safer & 0.53 & 0.48 & 0.62 & 0.55 & 0.55 & 0.68 & 0.32 \\
$\quad$ Riskier & 0.47 & 0.52 & 0.38 & 0.45 & 0.45 & 0.32 & 0.68 \\
Obs. (subjects) & 466 & 84 & 79 & 76 & 73 & 74 & 80 \\
\hline Sharing & 0.70 & 0.71 & 0.65 & 0.74 & 0.81 & 0.66 & 0.71 \\
Obs. (decisions) & 946 & 252 & 237 & 76 & 73 & 148 & 160 \\
\hline
\end{tabular}

Notes: proportions presented; mismatch in risk exposure between choosers and chosen-for players under IDSG is owing to the sub-treatment assignment by badge picking combined with no-shows.

From the upper panel of Table 5 we can infer that 55 percent of choosers choose the safer gamble for their chosen-for co-player under IDSG and a significantly lower 32 percent of choosers choose the safer gamble for their chosen-for co-player under IDDG $(p<0.01)$.

The lower panel of Table 5 presents the proportions of "share" as opposed to "leave" decisions made under each of the RSG treatments. Overall, the proportion of "share" as opposed to "leave" decisions was 70 percent and variation across treatments was limited. ${ }^{11}$ According to ttests accounting for clustering at the session level, only the difference in the proportion between

\footnotetext{
${ }^{11}$ Controlling for village fixed effects leaves this result unchanged.
} 
CHOS, where the proportion was lowest, and IDSG chosen-for, where the proportion was highest, is significant $(p=0.06){ }^{12}$

\subsection{Is socially responsible risk taking rewarded? Is socially irresponsible risk taking punished?}

To test Predictions 1.1 and 1.2 we used the share-or-leave decisions made by subjects under $R A N D$ and chosen-for subjects under either IDSG or IDDG. Figure 1, Panel A graphs the proportions of subjects choosing to share under RAND (two bars on the right) and under IDSG chosen-for (two bars on the left). Panel B graphs the proportions of subjects choosing to share under RAND (two bars on the right) and under IDDG chosen-for (two bars on the left). The test results in Panels A and B are derived from the linear probability model (LPM) presented in column (1) of Table $6 .{ }^{13}$ An observation in this model is a share-or-leave decision. The dependent variable equals one if a subject chose to share and zero if they chose to leave the gamble payoffs unchanged. The explanatory variables IDSG-chosen-for and IDDG-chosen-for equal one if the decision was made by a chosen-for player under IDSG or IDDG respectively and zero otherwise. The explanatory variable riskier equals one if the decision-making subject faced the riskier gamble and zero if they faced the safer gamble.

\footnotetext{
12 The difference becomes insignificant once village fixed effects are controlled for.

${ }^{13}$ An LPM is estimated rather than a Probit or Logit because all of the explanatory variables are zero-one. Probit and Logit estimations yield very similar results.
} 
Table 6: Sharing by subjects who are assigned their risk exposure: linear probability model estimations

Dependent variable $=1$ if $i$ chose to share, $=0$ if $i$ chose to leave

\begin{tabular}{|c|c|c|c|c|}
\hline & (1) & (2) & (3) & (4) \\
\hline riskier $_{i}$ & $\begin{array}{c}0.147 \\
(0.080)\end{array}$ & $\begin{array}{l}0.147^{*} \\
(0.080)\end{array}$ & $\begin{array}{c}0.108 \\
(0.180)\end{array}$ & $\begin{array}{c}0.120 \\
(0.071)\end{array}$ \\
\hline IDSG-chosen-for $i$ & $\begin{array}{l}0.167^{* *} \\
(0.079)\end{array}$ & - & - & - \\
\hline$I D D G$-chosen-for $i$ & $\begin{array}{l}0.117 \\
(0.073)\end{array}$ & - & - & - \\
\hline chosen-for $r_{i}$ & - & $\begin{array}{c}0.138^{* *} \\
(0.058)\end{array}$ & $\begin{array}{c}0.390^{* *} \\
(0.168)\end{array}$ & $\begin{array}{c}0.199 * * \\
(0.086)\end{array}$ \\
\hline riskier $_{i} * I D S G$-chosen-for $i$ & $\begin{array}{l}-0.129 \\
(0.121)\end{array}$ & - & - & - \\
\hline riskier $_{i} * I D D G$-chosen-for ${ }_{i}$ & $\begin{array}{c}-0.212 * * \\
(0.103)\end{array}$ & - & - & - \\
\hline riskier $_{i} *$ chosen for $_{i}$ & - & $\begin{array}{c}-0.202 * * \\
(0.097)\end{array}$ & $\begin{array}{l}-0.337 \\
(0.223)\end{array}$ & $\begin{array}{r}-0.219 * * \\
(0.097) \\
\end{array}$ \\
\hline$R A_{i}$ & - & - & $\begin{array}{c}0.111 \\
(0.261)\end{array}$ & - \\
\hline riskier $_{i} * R A_{i}$ & - & - & $\begin{array}{c}0.050 \\
(0.286)\end{array}$ & - \\
\hline chosen-for ${ }_{i} * R A_{i}$ & - & - & $\begin{array}{l}-0.475 \\
(0.318)\end{array}$ & - \\
\hline riskier $_{i}{ }^{*}$ chosen for ${ }_{i} * R A_{i}$ & - & - & $\begin{array}{c}0.276 \\
(0.354) \\
\end{array}$ & - \\
\hline$\overline{\text { Same gamble }_{i}}$ & - & - & - & $\begin{array}{c}0.041 \\
(0.031)\end{array}$ \\
\hline Diff. in gamble payoff $i$ & - & - & - & $\begin{array}{l}3.1 \mathrm{e}^{-5} \\
\left(6.5 \mathrm{e}^{-5}\right)\end{array}$ \\
\hline Household head & & & & $\begin{array}{l}0.071 \\
(0.128)\end{array}$ \\
\hline Female $_{i}$ & - & - & - & $\begin{array}{l}-0.058 \\
(0.127)\end{array}$ \\
\hline $\mathrm{Age}_{i}$ & - & - & - & $\begin{array}{l}-6.5 \mathrm{e}^{-4} \\
(0.002)\end{array}$ \\
\hline Education $_{i}$ & - & - & - & $\begin{array}{c}0.009 \\
(0.010)\end{array}$ \\
\hline${\text { Household } \text { income }_{i}}$ & - & - & - & $\begin{array}{l}7.0 \mathrm{e}^{-8} \\
\left(9.0 \mathrm{e}^{-8}\right)\end{array}$ \\
\hline Constant & $\begin{array}{c}0.633 * * * \\
(0.030)\end{array}$ & $\begin{array}{c}0.633 * * * \\
(0.030)\end{array}$ & $\begin{array}{c}0.576^{* * * *} \\
(0.142)\end{array}$ & - \\
\hline Village fes & No & no & no & yes \\
\hline $\begin{array}{l}\text { Linear restriction test of } \\
\mathrm{H}_{0}: \text { Model } 2 \text { (p-value) }\end{array}$ & 0.303 & - & 0.143 & $<0.01$ \\
\hline $\begin{array}{l}\text { R-squared } \\
\text { Obs. }\end{array}$ & $\begin{array}{c}0.022 \\
485\end{array}$ & 0.017 & $\begin{array}{c}0.028 \\
485\end{array}$ & $\begin{array}{c}0.077 \\
477\end{array}$ \\
\hline
\end{tabular}


Figure 1: Chosen-for players' sharing decisions

Panel A.

RAND and IDSG chosen-for

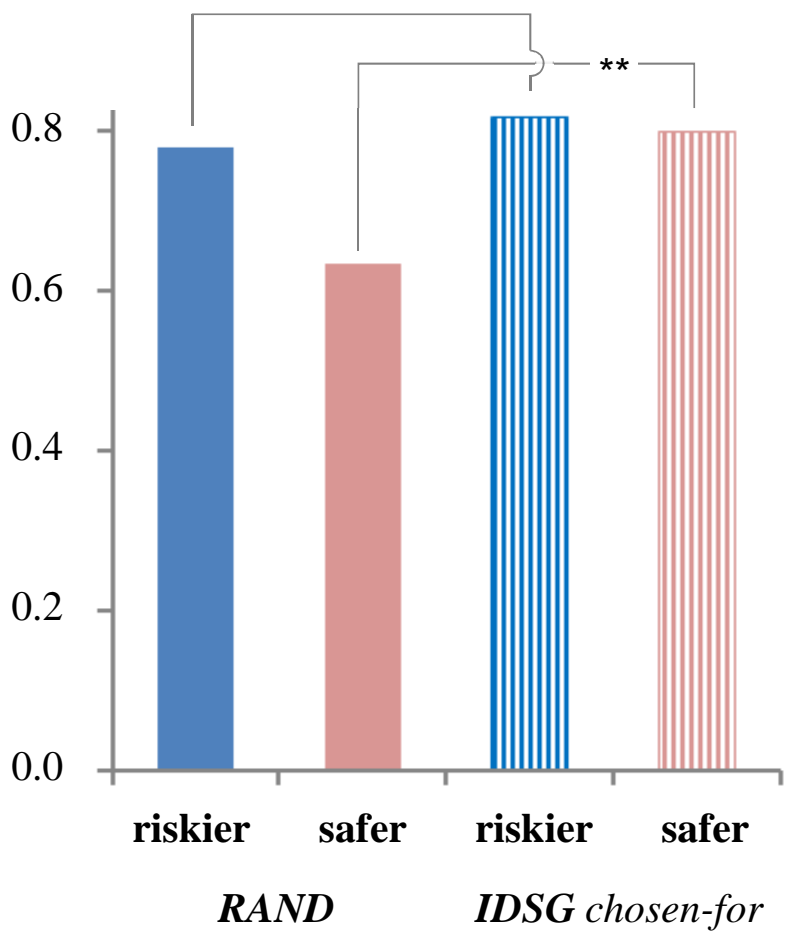

Panel B.

RAND and IDDG chosen-for

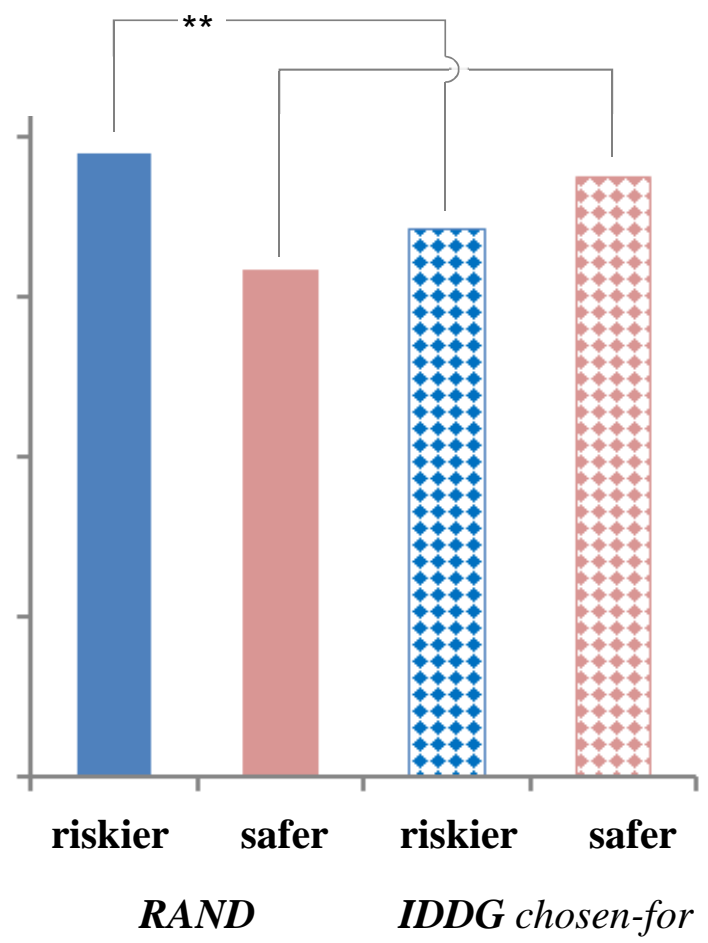

Panel C.

RAND and chosen-for pooled across IDSG and IDDG

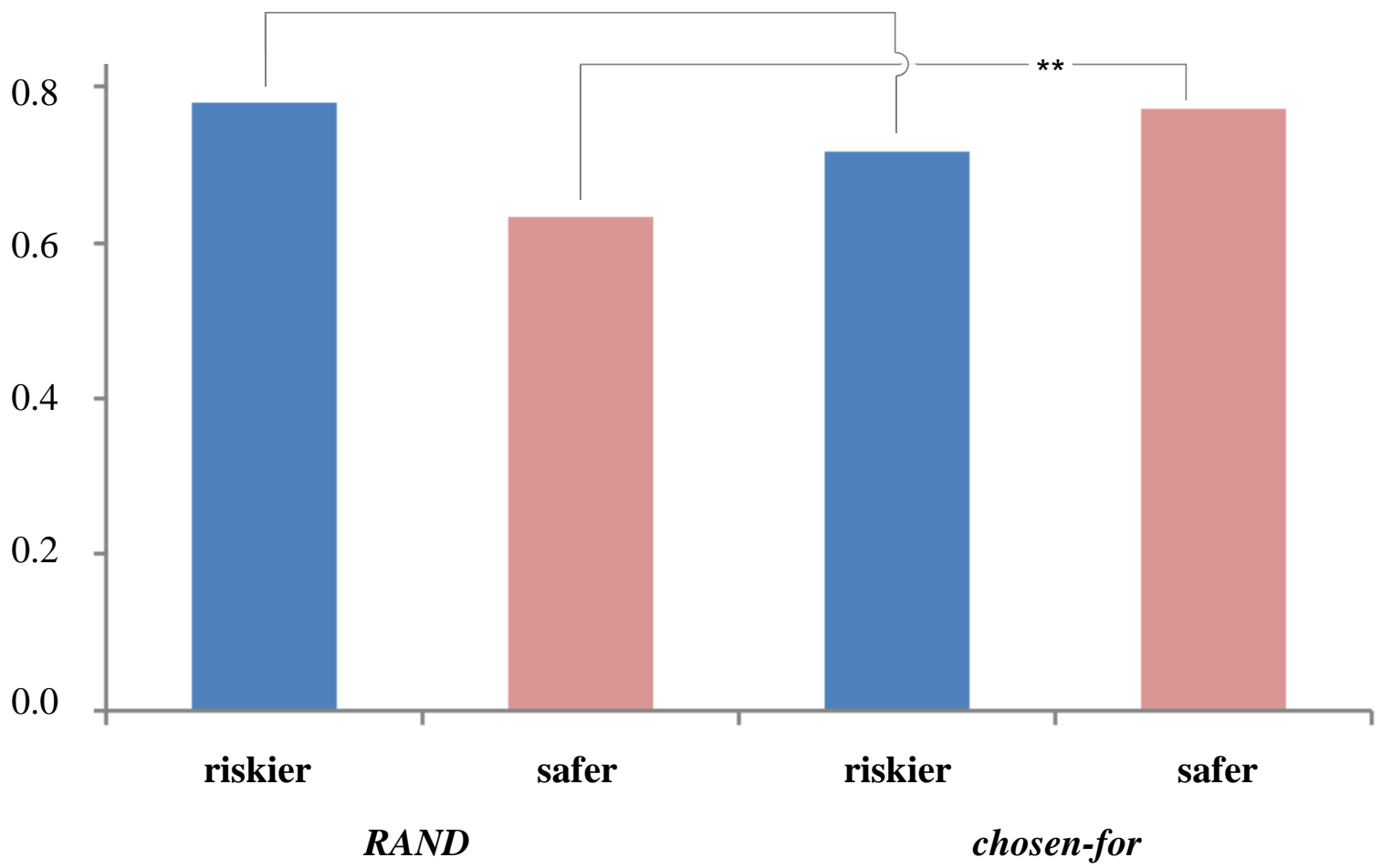

Notes: Bar heights are proportions of chosen-for players sharing in each sub-sample; test results derived from LPM in columns (1) and (2) of Table 6; ** $p<0.05$. 
Panel A shows that the chosen-for players who were assigned the safer gamble by their chooser co-players under $I D S G$ were significantly more likely to share gamble payoffs compared to subjects who were randomly assigned the safer gamble under RAND. However, there was no difference in sharing rates between the chosen-for who were assigned the riskier gamble by their chooser co-players under IDSG, and subjects who were randomly assigned the riskier gamble under RAND. Panel B shows that the chosen-for players who were assigned the riskier gamble by their chooser co-players under $I D D G$ were significantly less likely to share gamble payoffs compared to subjects who were randomly assigned the riskier gamble under RAND. However, the apparent difference in sharing rates between the chosen-for who were assigned the safer gamble by their chooser co-players under IDDG and subjects who were randomly assigned the safer gamble under $R A N D$, while consistent with the prediction, is not significant.

Figure 1, Panel $\mathrm{C}$ graphs the proportions of subjects choosing to share under RAND (two bars on the right) and under either IDSG chosen-for or IDDG chosen-for (two bars on the left), i.e., in Panel C the decisions of the IDSG chosen-for and IDDG chosen-for players have been pooled. The test result in Panel C is derived from the LPM in Column 2 of Table 6. The LPM in Column 2 is a restricted version of the LPM in Column 1. A linear restriction test based on these two LPMs indicates that we cannot reject the null that the coefficients on IDSG chosenfor and IDDG chosen-for are equal to one another and the coefficients on riskier interacted with each of IDSG chosen-for and IDDG chosen-for are equal to one another. So, the LPM in Column 2 of Table 6 and the corresponding graphs in Panel C of Figure 1 are preferred.

Panel C shows that the chosen-for players who were assigned the safer gamble by their chooser co-players were significantly more likely to share gamble payoffs compared to subjects who were randomly assigned the safer gamble under RAND. However, there was no difference in 
sharing rates between the chosen-for players who were assigned the riskier gamble by their chooser co-players and subjects who were randomly assigned the riskier gamble under RAND.

In Column 3 of Table 6, we investigate whether chosen-for players' levels of risk aversion affect their inclinations to reward (punish) socially (ir)responsible risk taking on the part of their chooser co-players. Introducing the Cole et al. measure of risk aversion $(R A)$ and its interactions with chosen-for, riskier and both perturbs the coefficients on chosen-for and the interaction between chosen-for and riskier and renders the latter statistically insignificant. However, according to a linear restriction test, $R A$ and its interactions are jointly insignificant $(p=0.143)$. So, the LPM in Column (2) remains preferred. ${ }^{14}$

In Column 4 of Table 6, we return to the preferred LPM and add two controls from the experimental data, five demographic controls, and village fixed effects. The experimental control Same gamble equals one if the decisions-maker faced the same gamble as her co-player and zero otherwise. It is included because Cappelen et al. (2013) found that individuals redistributed more towards equality when co-players chose the same level of risk exposure. ${ }^{15}$ The experimental control Difference in gamble payoff is included because the cost of sharing is increasing in this difference. Household headship, sex, age, education, and household income are included to control for the effects of individual characteristics on willingness to share. The village fixed effects are included to control for many factors including differences in villagelevel culture.

\footnotetext{
${ }^{14}$ Using a dummy variable indicating that $i$ chose one of the three least risk gambles in the GC, yields very similar results (see Table A1 in the On-line supplementary materials).

${ }^{15}$ Cettolin and Tausch (2015) found a similar tendency in ex ante risk sharing among subjects who chose relatively low risk exposure for themselves.
} 
The set of controls is jointly highly significant $(p<0.01)$, principally owing to the high joint significance of the village fixed effects $(p<0.01)$. However, the inclusion of the controls leaves the coefficients on riskier, chosen-for and their interaction unchanged in terms of sign and, while the coefficient on riskier has lost significance, the coefficients on chosen-for and the interaction have retained their significance and increased in absolute magnitude. This LPM indicates, once again, that chosen-for players who were assigned the safer gamble by chooser co-players were significantly more likely to share payoffs compared to subjects who were randomly assigned the safer gamble under RAND. However, on average, there was no difference in sharing rates between the chosen-for players who were assigned the riskier gamble by their chooser co-players and subjects who were randomly assigned the riskier gamble under RAND.

To sum up, Predictions 1.1 and 1.2 are supported. Choosers are rewarded for choosing the safer gamble for their chosen-for co-players, especially under IDSG, and under IDDG choosers are punished for choosing the riskier gamble for their chosen-for co-players.

\subsection{Is social responsibility in risk taking cost-dependent?}

The results of the comparative t-test analysis of risk exposure presented in Table 5 are inconsistent with Predictions 2.1 and 2.3. However, Predictions 2.2 and 2.4, which focus on how the cross-treatment differences vary with the level of risk aversion, have yet to be tested. To test Predictions 2.2 and 2.4 we estimate a Logit model using the RSG gamble choice decisions made by subjects under CHOS and choosers under either IDSG or IDDG. The dependent variable equals one if a subject chose the safer gamble for herself and zero otherwise. The explanatory variables are IDSG-chooser and IDDG-chooser, which equal one if the decision was made by a chooser player under IDSG or IDDG respectively and zero otherwise, 
the decision-maker's level of risk aversion, $R A$, and pairwise interactions between $R A$ and the two treatment identifiers. Table 7, Column 1 presents the resulting estimated average marginal effects of $R A$ on the likelihood of a subject choosing the safer gamble for herself and the predicted likelihoods of a subject making such a choice given $R A=0$ and $R A=1$ under each treatment. Figure 2, Panel A plots the predicted likelihoods of a subject making such a choice, and the alternative, given every level of risk aversion in the data under each treatment.

Column 1 of Table 7 and Panel A of Figure 2 indicate that the likelihood of a subject choosing the safer gamble for herself is increasing in her level of risk aversion, but that the relationship is significant only under IDSG $(p<0.01)$. They also indicate that, in accordance with Predictions 2.2 and 2.4, the marginal effects of a subject's level of risk aversion on the likelihood of her choosing the safer gamble for herself is greater under IDSG and IDDG compared to CHOS. However, in neither instance is the difference statistically significant.

Column 2 of Table 7 presents the results of estimating a version of the Logit model that also includes the characteristics of the decision-making subject and village fixed effects. These controls are jointly highly significant $(p<0.01)$ owing to the high joint significance of the village fixed effects $(p<0.01)$. However, their inclusion has little impact on the effects of principle interest. $^{16}$

\footnotetext{
${ }^{16}$ Using a dummy variable indicating that $i$ chose one of the three least risk gambles in the GC, yields very similar results (see Table A2 in the On-line supplementary materials).
} 
Table 7: The effect of risk aversion on choice of RSG gamble for self: Logit estimations Dependent variable $=1$ if $i$ chose the safer gamble for herself, $=0$ otherwise

(1)

Under $\mathrm{CHOS}$ :

Average marginal effect of $R A_{i}$

Likelihood of choosing safer for self when $R A_{i}=0$

Likelihood of choosing safer for self when $R A_{i}=1$

Under IDSG-chooser:

Average marginal effect of $R A_{i}$

Likelihood of choosing safer for self when $R A_{i}=0$

Likelihood of choosing safer for self when $R A_{i}=1$

Average marginal effect of $R A_{i}$

0.153

(0.336)

0.527

0.691

(2)

0.148

(0.335)

0.487

$0.679 * * *$

$(0.216)$

0.208

0.852

0.474

\section{Under IDDG-chooser:}

Likelihood of choosing safer for self when $R A_{i}=0$

(0.285)

0.420

0.862

Likelihood of choosing safer for self when $R A_{i}=1$

\begin{tabular}{|c|c|c|}
\hline Household head $_{i}$ & - & $\begin{array}{l}-0.039 \\
(0.105)\end{array}$ \\
\hline Female $_{i}$ & - & $\begin{array}{l}0.056 \\
(0.097)\end{array}$ \\
\hline $\mathrm{Age}_{i}$ & - & $\begin{array}{c}0.003 \\
(0.003)\end{array}$ \\
\hline Education $_{i}$ & - & $\begin{array}{c}0.009 \\
(0.012)\end{array}$ \\
\hline${\text { Household } \text { income }_{i}}$ & - & $\begin{array}{l}1.73 \mathrm{e}^{-4} \\
\left(1.28 \mathrm{e}^{-4}\right)\end{array}$ \\
\hline $\begin{array}{l}\text { Village fixed effects } \\
\text { Joint sig of village fes ( } p \text {-value) }\end{array}$ & No & $\begin{array}{l}\text { Yes } \\
<0.001\end{array}$ \\
\hline $\begin{array}{l}\text { Linear restriction tests of: } \\
\mathrm{H}_{0} \text { : effect of } R A_{i} \text { under } C H O S \text { and } \\
\qquad I D S G \text { the same (p-value) }\end{array}$ & $(0.196)$ & $(0.105)$ \\
\hline $\begin{array}{l}\mathrm{H}_{0}: \text { effect of } R A_{i} \text { under } C H O S \text { and } \\
I D D G \text { the same (p-value) }\end{array}$ & $(0.477)$ & $(0.495)$ \\
\hline $\begin{array}{l}\text { Pseudo R-squared } \\
\text { Obs. }\end{array}$ & $\begin{array}{c}0.023 \\
229\end{array}$ & $\begin{array}{c}0.101 \\
228\end{array}$ \\
\hline
\end{tabular}

$0.764 * * *$

(0.186)

0.185

0.870
0.469

(0.311)

0.432

0.886 
Finally, Table 7 and Panel A of Figure 2 yield some insights relating to Predictions 2.1 and 2.3. In accordance with Prediction 2.1, risk averse choosers under IDSG were more likely (though not significantly so) to choose the safer gamble for themselves compared to risk averse subjects under CHOS. However, in conflict with Prediction 2.1, risk tolerant choosers under IDSG were less likely (though not significantly so) to choose the safer gamble for themselves compared to risk tolerant subjects under $\mathrm{CHOS}$. Further, in accordance with Prediction 2.3, risk tolerant choosers under $I D D G$ were less likely (though not significantly so) to choose the safer gamble for themselves compared to risk tolerant subjects under CHOS. However, in conflict with Prediction 2.3, risk averse choosers under IDDG were more likely (though not significantly so) to choose the safer gamble for themselves compared to subjects under $C H O S$.

To sum up, while there are regularities in the data that are consistent with Predictions 2.1 to 2.4 and, hence, with the conjecture that socially responsible risk taking is cost-dependent, the statistical evidence is patchy and weak. In part, the failure of the predictions appears to be owing to the choosers for whom socially responsible risk taking is most costly erring towards social irresponsibility, choosing the riskier gamble for their chosen-for co-players because, in so doing, they secure their preferred gamble for themselves.

One possible explanation as to why choosers for whom socially responsible risk taking is most costly might err towards socially irresponsible risk-taking is that they can share ex post instead. This brings us to our final research question.

\subsection{Are social responsibility in risk taking and sharing substitutes?}

To test Prediction 3.1, we use the gamble choice and sharing decisions made by choosers under

$I D S G$ and $I D D G$. We generate a new variable that equals one if a chooser under IDSG chose 
the safer gamble for herself and, hence, also for her chosen-for co-player, one if a chooser under $I D D G$ chose the riskier gamble for herself and, hence, the safer gamble for her chosen-for coplayer, and zero otherwise. This new variable is positively correlated with the decision to share and, according to a Chi-squared test, the correlation is significant $(p=0.017)$. A simple bivariate regression indicates that the correlation remains significant once we account for clustering at the session-level and that choosing the safer gamble for a chosen-for co-player is associated with a 0.15 increase in the likelihood of sharing gamble payoffs equally with that co-player. Finally, once village-level variations in sharing are accounted for, choosing the safer gamble for a chosen-for co-player is associated with a 0.19 increase in the likelihood of sharing.

To gain some insights into what is driving this positive correlation, we return to the Logit models presented above and break the dependent variable down into the following four categories: choose safer for self and share; choose safer for self and leave; choose riskier for self and share; and choose riskier for self and leave. Then, instead of Logit estimations, we conduct multinomial Logit estimations. The upper panel of Table 8 presents a model without controls, Model 1. The lower panel presents a model with controls including village fixed effects, Model 2. Model 2 makes use of the sub-sample of decisions made in villages in which two out of the three relevant treatments, $C H O S, I D S G$ and $I D D G$, were conducted ${ }^{17}$ Once again, the village fixed effects are jointly highly significant $(p<0.01)$. Also, while all the coefficients on the subjects' characteristics are individually insignificant, they too are jointly highly significant $(p<0.01)$. The size and significance of the effects of principle interest do vary between the models in the upper and lower panel. However, the signs of the effects remain the

\footnotetext{
${ }^{17}$ If we include decisions made in villages in which only one out of the three relevant treatments were conducted, the model with village fixed effects does not converge.
} 
same and the set of effects that are significant at the 10 percent level or better is unchanged. ${ }^{18}$ For this reason, because Model 2 is supported by an incomplete sample, and for consistency with Panel A, in Figure 2, Panel B we plot the predicted likelihoods of a subject making each of the possible combined gamble and share-or-leave choices derived from Model 1.

Consistent with the positive correlation reported above, Figure 2, Panel B, reveals that risk tolerant choosers under IDSG were considerably more likely to choose the riskier gamble for themselves and leave compared to risk tolerant subjects under CHOS. In contrast, but also consistent with the positive correlation, risk averse choosers under IDSG were considerably more likely to choose the safer gamble for themselves and share compared to risk averse subjects under $C H O S$.

To sum up, Prediction 3.1 is not supported. Socially responsible risk taking and sharing are positively correlated, indicating that they are not substitutes. The positive correlation is most pronounced under IDSG, where risk averse choosers tend to engage in both socially responsible risk taking and sharing and risk tolerant choosers tend to engage in neither.

\footnotetext{
${ }^{18}$ In this case, using a dummy variable indicating that $i$ chose one of the three least risk gambles in the GC, yields fewer significant results (see Table A3 in the On-line supplementary materials), indicating that dichotomising the risk aversion measure eliminates information that is useful for understanding the co-determination of risk-taking and sharing.
} 
Table 8: Risk taking and sharing, multinomial logit estimations

Dependent variable $\in\{$ Safer for self and share, Safer for self and share,

Riskier for self and leave, Riskier for self and leave\}

Basis for comparison $=$ Safer for self and share

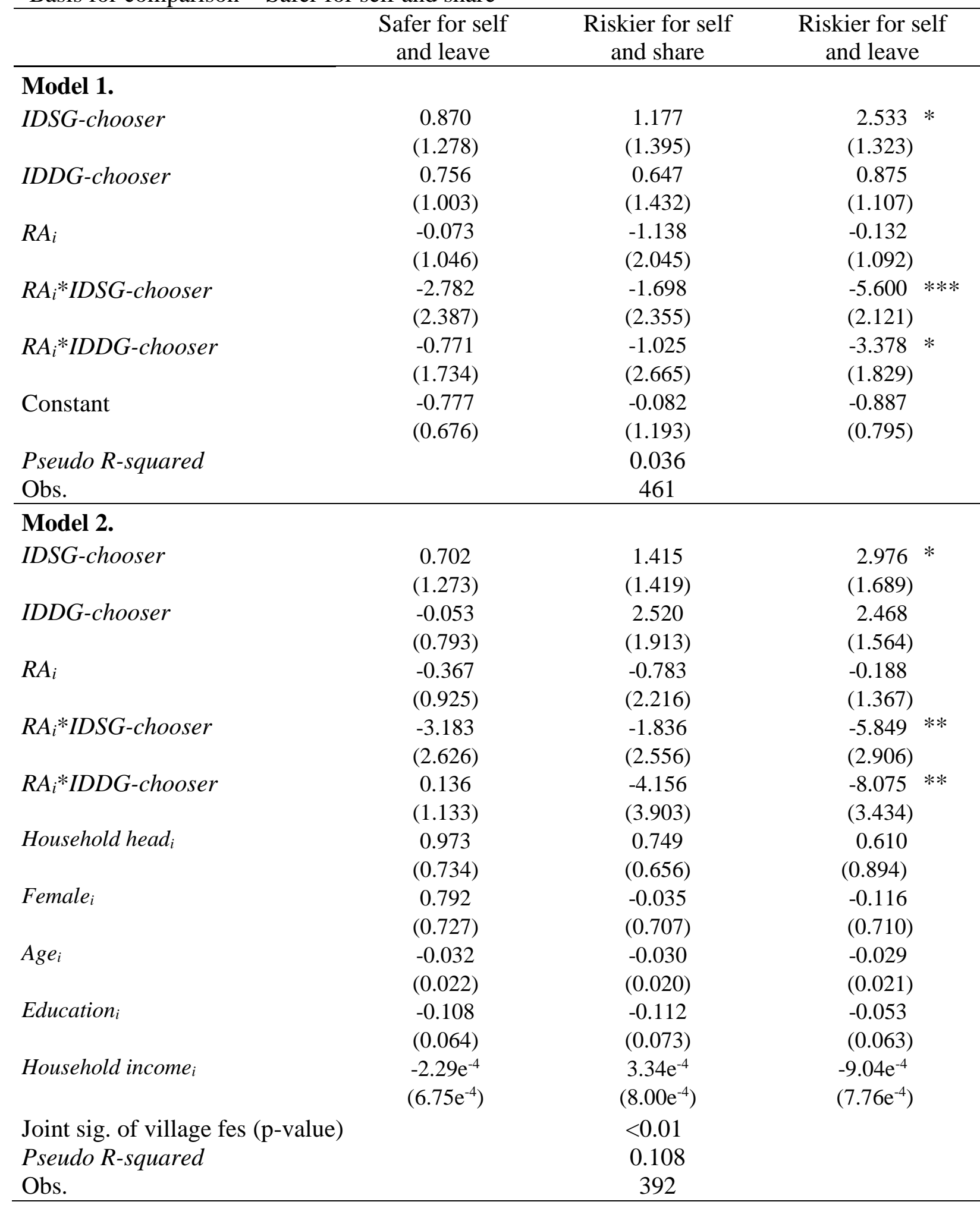

Notes: Base for comparison is Safer for self + share; an observation is a subject facing a scenario; coefficients and standard errors presented; *** $p<0.01 ; * * p<0.05 ; * p<0.10$. 
Figure 2: Choosers' risk taking and sharing decisions

Panel A . Risk taking

CHOS

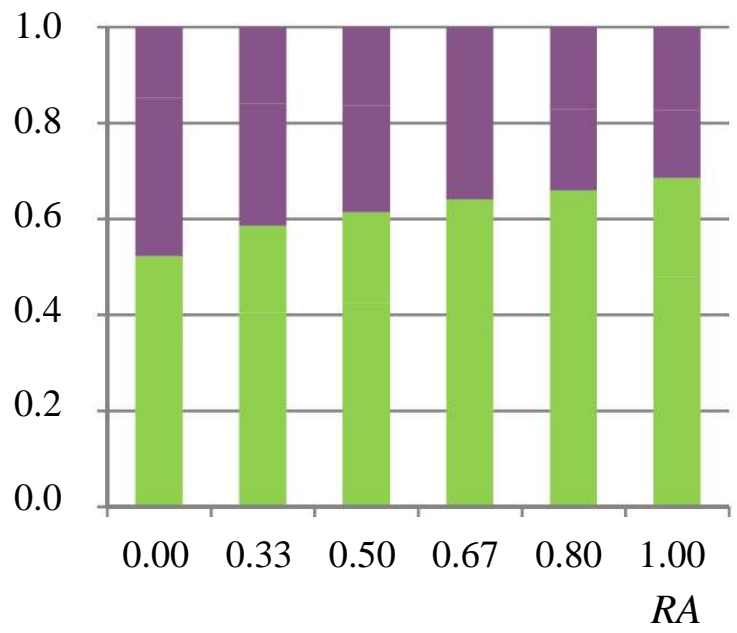

IDSG chooser

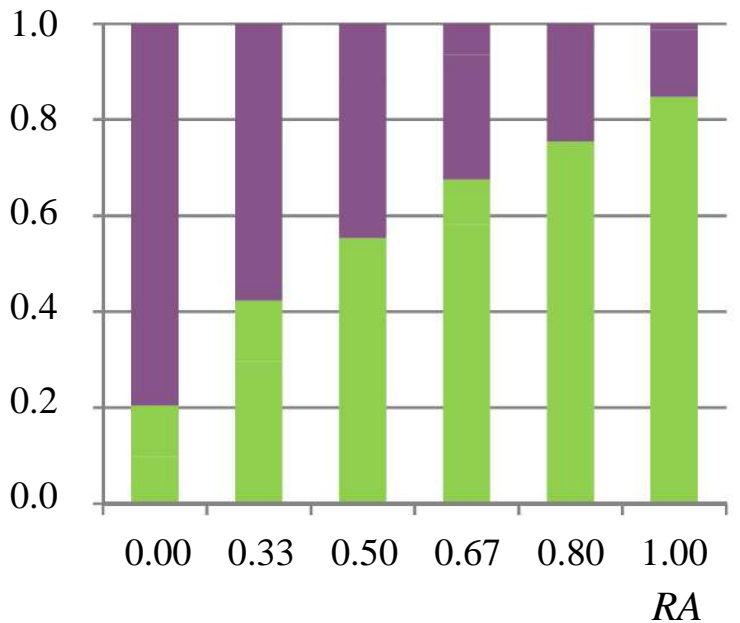

IDDG chooser

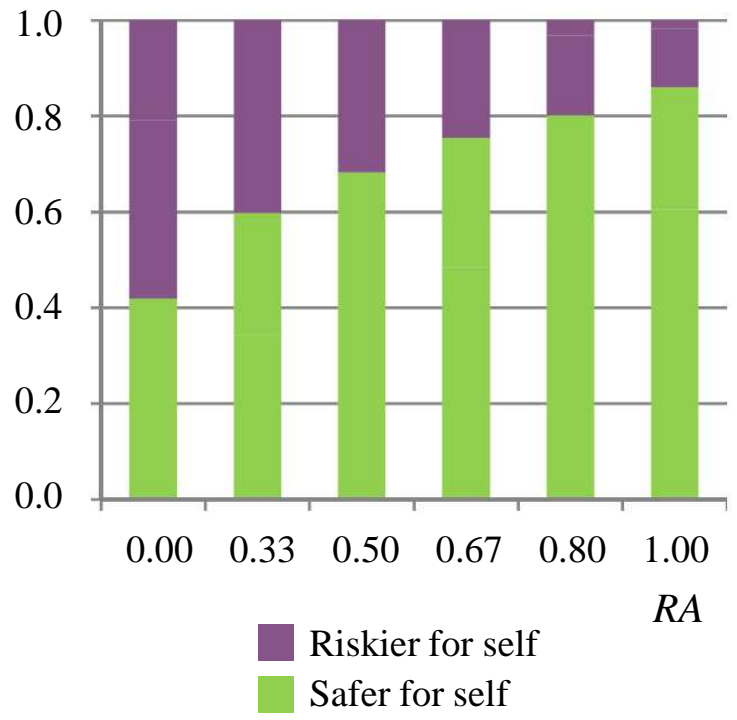

Panel B. Risk taking and sharing

CHOS

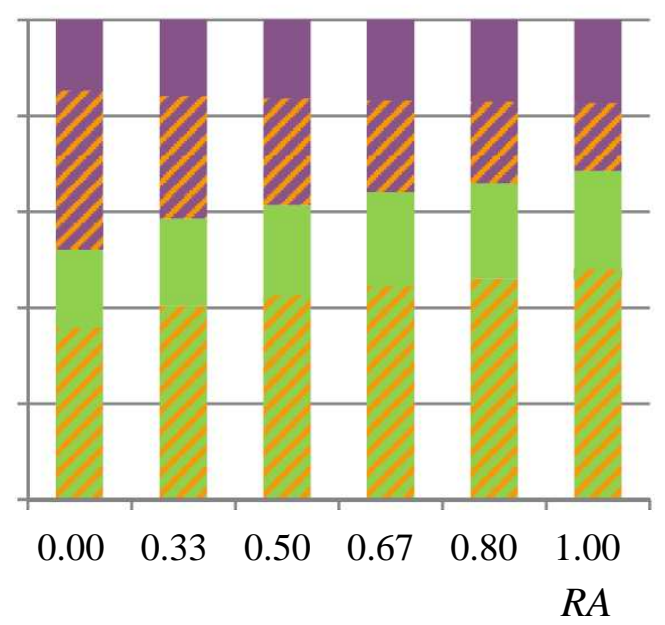

IDSG chooser

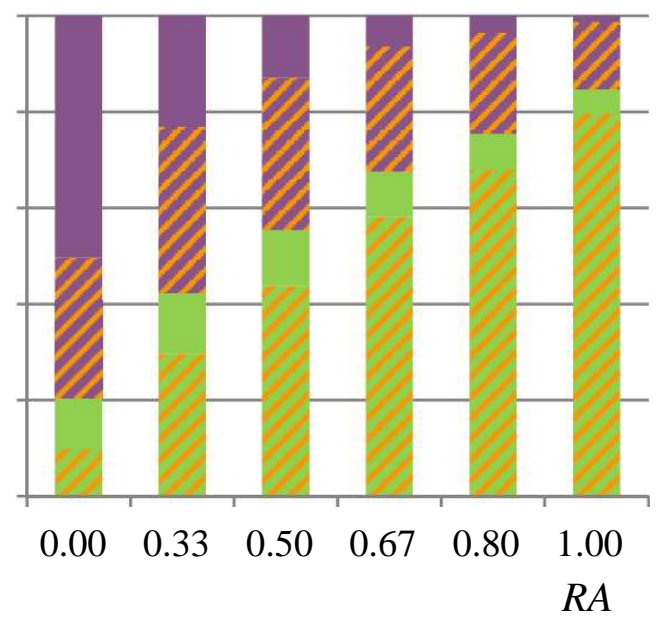

IDDG chooser

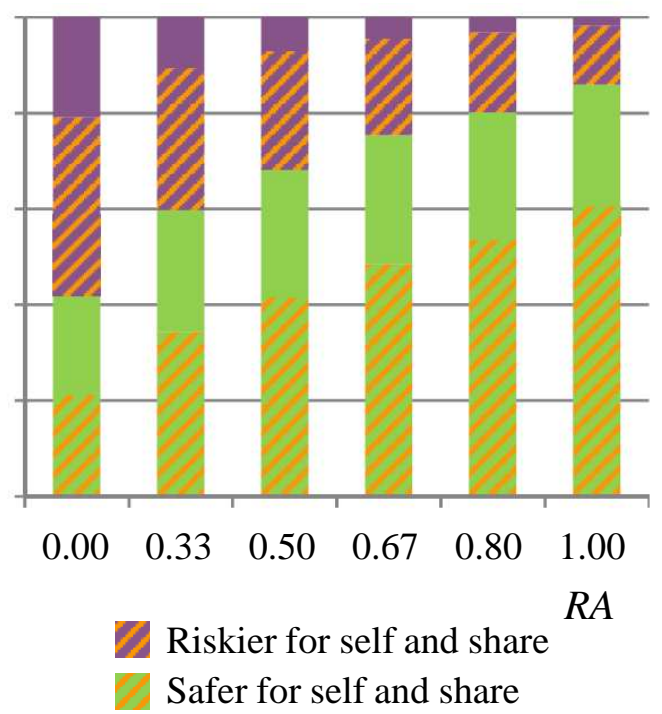

Notes: Panel A derived from Logit estimation in column (1) of Table 7; Panel B derived from multinomial Logit estimation in upper panel of Table 8 . 


\subsection{The meaning of socially responsible risk taking to Sri Lankan farmers}

So, what do the findings presented above tell us about what socially responsible risk taking means to Sri Lankan farmers? Earlier we proposed that, within the context of the RSG, socially responsible risk taking could equate to either minimising the risk exposure of others or minimising the risk exposure of the pair. And we went on to argue that, under certain assumptions, if the second rather than the first of these meanings is apposite, we would find support for our predictions when focusing on IDSG, but not when focusing on IDDG.

The share-or-leave decisions of the chosen-for subjects under both IDSG and IDDG were consistent with socially responsible risk taking equating to minimising the risk exposure of others and being rewarded and/or not punished. So, the chosen-for Sri Lankan farmers were acting in accordance with the definition focused on what their co-players' risk taking decisions implied for them. However, while the RSG-gamble-choice decisions combined with the shareor-leave decisions of the choosers under IDSG systematically differed from those of subjects under $C H O S$, there was visually less and statistically no difference between choosers under $I D D G$ and subjects under $C H O S$. So, the chooser Sri Lankan farmers may have been acting in accordance with the definition focussing on what their risk taking decisions implied for the pair.

\section{Conclusion}

Within the context of our experiment, we found that choosers were rewarded for choosing the safer gamble for their chosen-for co-players, especially when choosers and chosen-for players faced the same risk. Further and relatedly, choosers were punished for choosing the riskier gamble for their chosen-for co-players when, as a consequence, they (the choosers) faced the safer gamble. These findings indicate that socially responsible risk taking is rewarded and socially irresponsible risk taking punished. 
With regard to the farmers' risk taking decisions, while there were regularities in the data that were consistent with the conjecture that socially responsible risk taking is cost-dependent, the statistical evidence was patchy and weak. In part, this was owing to the choosers for whom socially responsible risk taking was most costly erring towards social irresponsibility, that is, choosing the riskier gamble for their chosen-for co-players because, in so doing, they secured their preferred gamble for themselves.

Finally, we found that socially responsible risk taking and sharing were positively correlated, indicating that they are not substitutes and that they may be co-determined.

Given that socially responsible risk taking is rewarded, socially irresponsible risk taking is punished and socially responsible risk taking and sharing are positively correlated within individuals, efforts to promote socially responsible risk taking may, at the same time, strengthen traditional forms of risk pooling. Further work is needed before firm conclusions can be drawn about how the cost of socially responsible risk taking to individuals, in terms of the opportunities they may have to forgo or the risks they may have to endure, impact on risk taking but our findings suggest that risk taking will turn out to be predictable in this regard.

Finally, it is worth noting that, despite the one-shot anonymous nature of the decision-making context into which they were placed, the Sri Lankan farmers demonstrated a very high degree of solidarity; they choose to share in 70 percent of the scenarios described to them in which they turned out to be the richer player. 


\section{References}

Baettig, M.B., Wild, M. and Imboden, D.M. (2007). A climate change index: Where climate change may be most prominent in the 21st century. Geophysical Research Letters. 34(1).

Baker, R.J., Laury, S.K., and Williams, A.W. (2008). Comparing small-group and individual behavior in lottery-choice experiments. Southern Economic Journal. 75, 367-382.

Barrett, C. B., Reardon, T. and Webb, P. (2001). Nonfarm Income Diversification and Household Livelihood Strategies in Rural Africa: Concepts, Dynamics, and Policy Implications. Food Policy, 26(4), 315-331.

Bicchieri, C. 2006. The Grammar of Society: The Nature and Dynamics of Social Norms. New York: Cambridge University Press.

Binswanger, H. P. (1980). Attitudes Toward Risk: Experimental Measurement in Rural India. American Journal of Agricultural Economics, 62, 395-407.

Bolton, G. and Ockenfels, A. (2000). A Theory of Equity, Reciprocity, and Competition. The American Economic Review, 90(1), 166-193.

Bolton, G. E., Ockenfels, A. and Stauf, J. (2015). Social Responsibility Promotes Conservative Risk Behavior. European Economic Review, 74, 109-127.

Bramoullé, Y., and Kranton, R., (2007). Risk-Sharing Networks. Journal of Economic Behavior and Organization, 64(3), 275-94.

Brandts, J., and Charness, G. (2011) The strategy versus the direct-response method: a first survey of experimental comparisons. Experimental Economics, 14, 375-398.

Rondeau, D. and Bulte, E (2007). Wildlife Damage and Agriculture: A Dynamic Analysis of Compensation Schemes. American Journal of Agricultural Economics, 89(2), 490-507. 
Cappelen, A. W., Konow, J., Sørensen, E. Ø., and Tungodden, B. (2013). Just Luck: An Experimental Study of Risk Taking and Fairness. American Economic Review, 103(4), 13981413.

Cettolin, E. and Tausch, F. (2015). Risk Taking and Risk Sharing: Does Responsibility Matter? Journal of Risk and Uncertainty, 50(3), 229-248.

Cole, S., Bastian, G., Vyas, S., Wendel, C., and Stein, D. (2012). The effectiveness of indexbased micro-insurance in helping smallholders manage weather-related risks. London: EPPICentre, Social Science Research Unit, Institute of Education, University of London.

Cole, S., Gine, X., Tobacman, J., Topalova, P., Townsend, R. and Vickery, J. (2013). Barriers to Household Risk Management: Evidence from India, Online Appendix. Accessed from: https://www.aeaweb.org/aej/app/app/2011-0326_app.pdf.

Cox, J. C. (2004). How to Identify Trust and Reciprocity. Games and Economic Behavior, 46, 260-281.

Cox, J. C., Friedman, D. and Gjerstad, S. (2007). A Tractable Model of Reciprocity and Fairness. Games and Economic Behavior, 59, 17-45.

de Janvry, A., Dequiedt, V. and Sadoulet, E. (2014). The Demand for Insurance Against Common Shocks. Journal of Development Economics, 106, 227-238.

Dercon, S. (2002). Income Risk, Coping Strategies, and Safety Nets. The World Bank Research Observer, 17(2), 141-166.

Dufwenberg, M. and Kirchsteiger, G. (2004). A Theory of Sequential Reciprocity. Games and Economic Behavior, 47, 268-298. 
Fafchamps, M., and Lund, S. (2003). Risk-sharing networks in rural Philippines. Journal of development Economics, 71(2), 261-287.

Fafchamps, M., (2011). Risk Sharing between Households, in Handbook of Social Economics, Benhabib, J., Bisin, A., and Jackson, M.O. (eds.), North-Holland, San Diego and Amsterdam.

Falk, A., Becker, A., Dohmen, T.J., Enke, B., Huffman, D. and Sunde, U. (2015). The Nature and Predictive Power of Preferences: Global Evidence. Research Memorandum No.039. Maastricht: University of Maastricht, Graduate School of Business and Economics.

Falk, A. and Fischbacher, U. (2006). A Theory of Reciprocity. Games and Economic Behavior, $54,293-315$.

Fehr, E., Fischbacher, U. and Gächter, S. (2002). Strong reciprocity, human cooperation, and the enforcement of social norms. Human nature, 13(1), 1-25.

Füssel, H. M. (2010). How inequitable is the global distribution of responsibility, capability, and vulnerability to climate change: A comprehensive indicator-based assessment. Global Environmental Change, 20(4), 597-611.

Greatrex, H., Hansen, J., Garvin, S., Diro, R., Blakeley, S., Le Guen, M., Rao, K. and Osgood, D. (2015). Scaling up index insurance for smallholder farmers: Recent evidence and insights. CGIAR Research Program on Climate Change, Agriculture and Food Security.

IPCC (2014). Climate Change 2014: Synthesis Report. Contribution of Working Groups I, II and III to the Fifth Assessment Report of the Inter-governmental Panel on Climate Change (Eds. R.K. Pachauri and L.A. Meyer). IPCC, Geneva, Switzerland.

Kebede, B. and Zizzo, D. (2011). Envy and Agricultural Innovation: An Experimental Case Study from Ethiopia. CSAE Working Paper Series 2011-06, Centre for the Study of African Economies, University of Oxford. 
Masclet, D., Colombier, N., Denant-Boemont, L, and Loheac, Y. (2009). Group and individual risk preferences: a lottery-choice experiment with self-employed and salaried workers. Journal of Economic Behavior and Organization, 70, 470-484.

Platteau, J.P., De Bock, O. and Gelade, W. (2017). The Demand for Microinsurance: A Literature Review. World Development, 94, 139-156.

Porter, C. (2012). Shocks, consumption and income diversification in rural Ethiopia. Journal of Development Studies, 48(9), 1209-1222.

Reynolds, D.B., Joseph, J., and Sherwood, R. (2009). Risky shift versus cautious shift: determining differences in risk taking between private and public management decisionmaking. Journal of Business \& Economics Research, 7(1), 63-77.

Rosenzweig, C., Elliott, J., Deryn, D., Ruanea, A.C., Müller, C., Arneth, A., Boote, K.J., Folberth, C., Glotter, M., Khabarov, N., Neumann, K., Piontek, F., Pugh, T.A.M., Schmid, E., Stehfest, E., Yang, H. and Jones J.W. (2014). Assessing agricultural risks of climate change in the 21st century in a global gridded crop model intercomparison, Proceedings of the National Academy of Sciences, 111(9), 3268-3273.

Sawada, Y., Nakata, H., and Kotera, T. (2017). Self-Production, Friction, and Risk Sharing against Disasters: Evidence from a Developing Country. World Development, 94, 27-37.

Selten, R. and Ockenfels, A. (1998). An Experimental Solidarity Game, Journal of Economic Behavior \& Organization, 34, 517-539.

Sherbinin, A. (2014). Climate change hotspots mapping: what have we learned? Climatic Change, 123(1), 23-37.

Shupp, R.S., and Williams, A.W. (2008). Risk Preference Differentials of Small Groups and Individuals. Economic Journal, 118, 258-283. 
Takasaki, Y., Barham, B.L., Coomes, O.T. (2004). Risk coping strategies in tropical forests: Floods, illnesses, and resource extraction. Environment and Development Economics, 9(2), 203-224.

Townsend, R. (1994). Risk and Insurance in Village India. Econometrica, 62(3), 539-591.

Udry, C., (1994). Risk and Insurance in a Rural Credit Market: An Empirical Investigation in Northern Nigeria. Review of Economic Studies, 61(3), 495-526.

Vieider, F. M., Villegas-Palacio, C., Martinsson, P., Mejía, M., (2016). Risk taking for oneself and others: A structural model approach. Economic Enquiry, 54(2), 879-894.

World Bank (2010). World Development Report 2010: Development and Climate Change. World Bank, Washington, DC.

Zizzo, D. and Oswald, A., (2001). Are People Willing to Pay to Reduce Others' Incomes? Annales d'Économie et de Statistique, 63/64, 39-65. 